\title{
Binary Cobalt and Magnesium Hydroxide Catalyst for Oxygen Evolution Reaction in Alkaline Water Electrolysis
}

\author{
Imgon Hwang ${ }^{1}$, Injoon Jang ${ }^{1}$, Gibaek Lee $e^{1,2}$ and Yongsug Tak ${ }^{1, *}$ \\ ${ }^{1}$ Department of Chemical Engineering, Inha University, 253 Yonghyun-dong, Nam-ku, Incheon 402- \\ 751, Republic of Korea \\ ${ }^{2}$ Department of Physics, Martin-Luther University of Halle-Wittenberg, Halle (Saale) 06099, Germany \\ *E-mail: ystak@inha.ac.kr
}

doi: $10.20964 / 2016.07 .69$

Received: 24 March 2016 / Accepted: 14 May 2016 / Published: 4 June 2016

\begin{abstract}
Alkaline water electrolysis has been proposed as an environmentally inoffensive way to supply the anticipated demand for hydrogen gas $\left(\mathrm{H}_{2}\right)$ for the prospective hydrogen energy economy. However, in practice, the efficiency of water electrolysis is limited by the large anodic overpotential of the oxygen evolution reaction (OER). Therefore, the development of catalysts having a low overpotential and high activity is required in order to reduce the cost and improve the efficiency of the alkaline OER. Herein, we focused on decreasing the overpotential and increasing the catalyst activity by simultaneous use of synthesized carbon-supported cobalt oxide and magnesium oxide as an electrochemical catalyst for the alkaline OER. The activity of the carbon-supported cobalt and magnesium hydroxide, $\mathrm{Co}(\mathrm{OH})_{2}-$ $\mathrm{Mg}(\mathrm{OH})_{2} / \mathrm{C}$, catalyst was dependent on the $\mathrm{pH}$ and metal composition ratio. The highest activity and lowest overpotential were achieved with the catalyst having a $\mathrm{Co}(\mathrm{OH})_{2}$ to $\mathrm{Mg}(\mathrm{OH})_{2}$ ratio of $84: 16$ prepared at $\mathrm{pH} 9.5$.
\end{abstract}

Keywords: $\mathrm{Mg}(\mathrm{OH})_{2}, \mathrm{Co}(\mathrm{OH})_{2}$, Oxygen evolution reaction, Alkaline water electrolysis, Carbon

\section{FULL TEXT}

(C) 2016 The Authors. Published by ESG (www.electrochemsci.org). This article is an open access article distributed under the terms and conditions of the Creative Commons Attribution license (http://creativecommons.org/licenses/by/4.0/). 